\title{
The Impact of Maternal Eating Disorders and Spousal support on Neurodevelopmental Trajectories in their Toddlers
}

\author{
Shiri Sadeh-Sharvit ${ }^{1,2 *}$, Rachel Levy-Shiff ${ }^{2}$, Katherine D Arnow ${ }^{1}$ and James D Lock ${ }^{1}$
}

${ }^{1}$ Department of Psychiatry and Behavioral Sciences, Stanford University, School of Medicine, Stanford, California

${ }^{2}$ Psychology Department, Bar Ilan University, Israel

\begin{abstract}
The early cognitive development of the toddlers of mothers with eating disorders is compromised. This exploratory study examined the role that the psychological and support resources of mothers with eating disorders may play in the developmental delay found in their toddlers. Twenty-nine mothers with prenatal eating disorders and their toddlers (18-24 months old) were case-control matched with no eating psychopathology mother-child dyads. Measures included maternal stress and organization of the home environment, spousal and extended social support, as well as a developmental assessment of the children. Results indicated that mothers with eating disorders history had higher parenting-related stress and poorer adaptation of the home setting to match the child's developmental needs. Extended social support was associated with improved child outcomes only in the case of low maternal stress, while spousal support was not associated with child outcomes regardless of maternal stress levels. These preliminary findings suggest that poorer maternal functioning and spousal support in mothers with eating disorders are linked with no adaptive neurodevelopmental trajectories in their young children. Future preventive intervention programs should focus on improving maternal, spousal and child functioning in these patients.
\end{abstract}

Keywords: Eating disorders; Intellectual development; Mother child relations; Risk factors; Support resources

\section{Introduction}

Parental mental disorders compromise parental functioning and are associated with greater negative cognitions and emotions about the parental role as well as with less adaptive parenting behaviors, including greater maternal stress, poorer availability to the child's needs and less age appropriate stimulation of the child [1,2]. Evidence also indicates a link between the type of parental and child mental difficulties [3]. Given that eating disorders are defined by pathological eating as well as significant shape and weight concerns, it stands to reason that this type of maternal mental disorder is empirically linked with over-preoccupation with the child's weight, many problems in feeding, and greater eating psychopathology in offspring as reported by both parents and children [4-8]. However, in addition to these specific risks of feeding and eating problems, maternal eating disorders may be associated with a broader impact on child outcomes.

Beyond their ability to provide their child with healthy, varied nutrition that lays the foundation for a developing brain, parents are key players in their children's cognitive development. Parents struggling with a mental disorder may find that the parental behaviors that facilitate early childhood intellectual development, namely flexible adaptation to the changing abilities and interests of their toddler, constitute a tremendous demand on their mental resources and add further stress that exacerbates typical parenting challenges [9]. Recently, an association was found between maternal eating disorder history and delayed cognitive and psychomotor development among their toddlers whose age was 18-42 months old [10]. However, the extent of this association may be reduced in elementary school children: in another study, 18 and 48 months old children whose mothers had anorexia nervosa had lower IQ scores, whereas children of the same sample, measured at 8 and 10 years old, demonstrated better intellectual functioning and working memory, but reduced control of attention compared to children whose mothers had bulimia nervosa or no eating psychopathology [11,12]. A potential explanation to these findings could be that the young children of mothers with eating disorders are exposed to unhealthy maternal eating patterns during pregnancy [13], and greater feeding difficulties in infancy and early childhood, when maternal concerns for the child's shape and weight often impact feeding $[11,14,15]$. Nonetheless, additional psychological factors likely play a role in early cognitive development. Another possible mechanism is the availability of cognitive scaffolding [16]. Maternal emotional distress compromises the provision of cognitively-stimulating home environment, which is linked to child outcomes [17]. Some recent studies of the interactions between mothers with eating disorders and their toddlers have highlighted higher maternal intrusiveness, control and conflict with respect to control dyads $[8,18]$. When the reciprocity between the mother and child is disturbed, maternal eating disorder symptoms may be indirectly connected with a developmental delay that is not feeding-based.

Parenting young children is a recognized stressor [19]. The stress associated with child-rearing responsibilities and pressures can negatively impact the mothers' sense of efficacy and well-being. In a previous study, mothers with histories of eating disorders demonstrated greater distress associates with their maternal role but their sense of maternal self-efficacy was not significantly different than mothers with

*Corresponding author: Sadeh-Sharvit S, Department of Psychiatry and Behavioral Sciences, Stanford University, School of Medicine, Stanford, California USA, Tel: (650) 479-4949, E-mail: shiris@stanford.edu

Received November 13, 2015; Accepted November 16, 2015; Published November 26, 2015

Citation: Sadeh-Sharvit S, Levy-Shiff R, Arnow KD, Lock JD (2015) The Impact of Maternal Eating Disorders and Spousal support on Neurodevelopmental Trajectories in their Toddlers. Abnorm Behav Psychol 1: 102. doi:10.4172/2472 0496.1000102

Copyright: () 2015 Sadeh-Sharvit S, et al. This is an open-access article distributed under the terms of the Creative Commons Attribution License, which permits unrestricted use, distribution, and reproduction in any medium, provided the original author and source are credited. 
no eating disorder history [20]. Thus, factors that improve maternal and child functioning should be further explored, and they may be found outside the mother-child dyad. The mother's social support network is mostly predictive of better maternal and offspring outcomes $[21,22]$. In fact, most family-based interventions identify and empower the support resources of parents within and outside the immediate family [23], by facilitating spousal communication skills and fostering available support resources [24-26].

The current study explored a new angle to understanding the factors associated with the delayed developmental trajectories found in the toddlers of mothers with eating disorders. Following previous findings of lower mental and psychomotor development among this group [10], we explored the role of three dimensions of maternal functioning present eating disorder severity, maternal stress, and the organization of the home environment - in order to elucidate their interplay in predicting toddlers' neurocognitive outcomes. We hypothesized that mothers with histories of eating disorders will have greater maternal stress and poorer adaptation of the home environment to the child's needs in comparison to mothers with no eating psychopathology. We also hypothesized that the spousal and extended social support will mitigate any negative associations found between maternal eating disorder history, maternal functioning, and child development.

\section{Method}

\section{Participants}

Twenty-nine mothers with histories of prenatal eating disorders and their toddlers (ages 18-42 months old) and twenty-nine mothers with no eating psychopathology and their toddlers participated in the current study. Mother-child dyads in the research and control groups were case-control matched according to the mother's education as well as the child's gender, age, and birth order. Table 1 presents the sample characteristics. Fourteen mothers in the research group had anorexia nervosa, thirteen had bulimia nervosa, and two mothers had a diagnosis of an eating disorder not otherwise specified according to DSM-IV criteria [27]. Thirty-four percent of the children were boys, and fifty-five percent were firstborn. All children were born full term and there was no difference in gestational weight gain during pregnancy. Seventeen mothers (59\%) in the research group were receiving outpatient treatment for their eating disorder during data collection and none were hospitalized at the time, whereas only three mothers $(10 \%)$ in the control group reported being in any medical or nutritional treatment during the research $\left(\chi^{2}=14.40, p<.001\right)$. Mothers in the research group reported the onset age of their eating disorder to be, on average, 14.07 years $(\mathrm{SD}=5.40)$ before they gave birth to the child with whom they participated in the study.

\section{Measures}

Maternal functioning: Mothers completed self-reports that assessed their psychological and maternal functioning. The Eating Disorders Inventory 2 (EDI-2; [28] measured the current eating disorder beliefs and symptoms. This is a 91-item questionnaire, in which higher scores indicate more extreme pathological attitudes towards food and weight. The degree of maternal stress associated with child rearing responsibilities and concerns was evaluated by The Parenting Stress Index-Short Form (PSI/SF; [29]), a 36-item tool in which higher scores indicate greater maternal stress. Cronbach's alphas were .95 for both the EDI and the PSI. The Home Observation for Measurement of the Environment Home [30] measured the degree to which the home milieu fits the developmental needs of toddlers. The

\begin{tabular}{|c|c|c|c|c|}
\hline \multirow[t]{2}{*}{ Variable } & \multicolumn{2}{|c|}{ Group } & \multirow[b]{2}{*}{$\mathbf{t}$} & \multirow[b]{2}{*}{$\begin{array}{c}\text { Effect } \\
\text { size }^{a}\end{array}$} \\
\hline & $\begin{array}{l}\text { Mothers } \\
\text { with EDs }\end{array}$ & $\begin{array}{c}\text { Mothers } \\
\text { without ED }\end{array}$ & & \\
\hline Mother age (years) & $\begin{array}{l}31.00 \\
(4.20)\end{array}$ & $\begin{array}{l}33.10 \\
(4.64)\end{array}$ & -1.73 & \\
\hline Child age (months) & $\begin{array}{l}32.50 \\
(7.20)\end{array}$ & $\begin{array}{l}30.60 \\
(7.30)\end{array}$ & 1.05 & \\
\hline Gestational weight gain (kg) & $\begin{array}{l}13.94 \\
(5.44)\end{array}$ & $\begin{array}{l}14.81 \\
(4.55)\end{array}$ & -.59 & \\
\hline $\begin{array}{l}\text { Current maternal eating disorders } \\
\text { symptoms }^{b}\end{array}$ & $\begin{array}{c}32.14 \\
(16.13)\end{array}$ & $\begin{array}{l}10.98 \\
(8.60)\end{array}$ & $6.58^{* * *}$ & 1.67 \\
\hline Current maternal BMI & $\begin{array}{l}21.44 \\
(4.67)\end{array}$ & $\begin{array}{l}24.21 \\
(5.63)\end{array}$ & -1.85 & \\
\hline Maternal stress $^{c}$ & $\begin{array}{l}2.40 \\
(.63)\end{array}$ & $\begin{array}{l}1.73 \\
(.32)\end{array}$ & $5.66^{* * *}$ & 1.36 \\
\hline $\begin{array}{l}\text { Organization of the home } \\
\text { environment }^{d}\end{array}$ & $\begin{array}{c}65.58 \\
(18.67)\end{array}$ & $\begin{array}{c}82.76 \\
(11.45)\end{array}$ & $-3.78^{* * *}$ & 1.13 \\
\hline Perceived partner support $^{e}$ & $\begin{array}{c}3.06 \\
(1.14)\end{array}$ & $\begin{array}{l}3.86 \\
(.75)\end{array}$ & $-4.0^{\star \star \star}$ & 0.7 \\
\hline $\begin{array}{l}\text { Perceived extended social } \\
\text { support }^{\mathrm{e}}\end{array}$ & $\begin{array}{l}2.87 \\
(.95)\end{array}$ & $\begin{array}{l}3.49 \\
(.82)\end{array}$ & $-2.81^{* * *}$ & 0.77 \\
\hline Child Mental Development Index ${ }^{f}$ & $\begin{array}{c}104.90 \\
(10.88)\end{array}$ & $\begin{array}{c}113.30 \\
(10.66)\end{array}$ & $-2.94^{\star \star}$ & .78 \\
\hline $\begin{array}{l}\text { Child Psychomotor Development } \\
\text { Index }\end{array}$ & $\begin{array}{l}102.83 \\
(9.69)\end{array}$ & $\begin{array}{l}112.41 \\
(10.83)\end{array}$ & $-3.24^{* * *}$ & .96 \\
\hline
\end{tabular}

${ }^{* *} p<.01,{ }^{* * *} p<.001$

a Effect sizes were calculated by means of Cohen's

b Measured by The Eating Disorders Inventory 2

c Measured by The Brief Symptom Inventory

d Home Environment

e Social support

f Assessed by The Bayley Scales of Infant Development II

Table 1: Paired t-tests comparing the mean (SD) scores and effects sizes of sample demographic and clinical characteristics, and children's mental and psychomotor development indices between mothers with and without history of prenatal eating disorders.

HOME is composed of 45 binary questions, scored by the researcher with the assistance of the mother, which assess the emotional and verbal responsiveness of the mother to the child, avoidance of restriction and punishment, provision of appropriate play materials, and the nature of the mother's involvement with the child and their daily stimulation. Higher scores indicate a more developmentally appropriate home environment. Cronbach's alpha was 89 .

Support networks: The Social Support Questionnaire [31] measured three ecological sources of support for the mother - from her spouse, her close environment (i.e., family relatives and friends), and psycho-medical professionals. Mothers rated the extent to which they receive tangible support, emotional support, and advice, as well as their satisfaction with receiving support from this source. Coefficient alphas in this sample were .88 (Partner Scale), .76 (Environment Scale), and .77 (Professionals Scale). Since so few participants were in any type of treatment at the time of the study (17 in the research group and only 3 in the control group), the psycho-medical support factor was not used as a measure. Two composite scores of social support were obtained by multiplying the extent-of-support indices by the relevant satisfaction indices, in which higher scores reflect a greater sense of support.

Child development: Toddler's neurodevelopment was assessed by The Bayley Scales of Infant Development-Second Edition [32], a widely used diagnostic tool in both clinical and research settings, in which Israeli and American norms are similar [33]. Table 1 presents the Mental Development Index (MDI) and the Psychomotor Development 
Index (PDI), as published in an earlier report (Authors, in press [a]). Raw scores of each index were transformed into standardized scores according to the child's age, with a mean score of $100(S D=15)$. Higher scores are indicative of more advanced development.

\section{Procedure}

The mothers in the eating disorder group were recruited from three specialized eating disorder treatment centers. The Institutional Research Board of each center approved the study. 108 patients who had children were identified, of whom 48 mothers had children who were younger or older than the age cutoff for the study. 19 patients could not be tracked, and an additional mother was excluded because her child was born preterm. Out of the remaining 40 eligible mothers, $29(72.5 \%)$ completed the full evaluation, $3(7.5 \%)$ participated in one meeting and then declined to continue, and $8(20 \%)$ refused to participate. The Eating Attitudes Test (EAT-26) [34] score cutoff of below 20 points was used to confirm a lack of an eating disorder among controls. The average EAT score in the eating disorders group was 29.56 $(S D=17.17)$, and $5.86(S D=6.17)$ in the control group: $\mathrm{t}=7.35, p<.001$, Cohen's $d=1.87$. After receiving both parents' informed consent for their child's participation in the study, the first author met with all of the mothers in their homes and administered the HOME and the BSID in a counterbalanced order.

\section{Statistical analysis}

A MANCOVA analysis did not indicate significant differences between mothers with different eating disorder diagnoses with respect to any of the study variables. Thus, all eating disorder participants were clustered into a single group for subsequent analyses, a method widely used in studies of mothers with eating disorders [4,20,35]. Significance values of .05 were used in all analyses. Group differences were tested with paired samples t-tests. Effect sizes were calculated by means of Cohen's $\mathrm{d}$ for significant differences, with $\geq 0.5$ indicating medium and $\geq 0.8$ large effect sizes.

A hierarchical linear regression analysis was performed for each child outcome to test the hypothesis that partner and extended social support would mitigate negative associations found between maternal eating disorder history, maternal functioning and child development. Therefore, variables in the first three steps were forced into the equation; in order to explore any potential interactions between variables, they were entered into the equation in a stepwise mode in step 4 , according to our hypotheses [36]. In Step 1, the research group (prenatal eating disorder vs. control) dummy variable was entered into the model, and in Step 2, maternal stress and organizations of the home environment were entered. Spousal and social support was entered in Step 3, and the interaction terms of any of the maternal and support variables were entered in Step 4. For any interactions that were significant, simple slope analyses were carried out. All analyses were performed using SPSS Statistics version 22.0 [37].

\section{Results}

\section{Group differences in maternal stress, organization of the home environment and support resources}

Paired t-tests indicated that the mothers with eating disorders group had greater maternal stress. They also organized the home environment in a less optimal manner when compared to the control mothers. Mothers with eating disorders reported receiving lower support from their spouse as well as from their extended social environment (Table 1).

\section{Predicting child neurodevelopmental outcomes from maternal eating disorder history, maternal functioning, and support resources}

The results of the two hierarchical linear regression analyses conducted to explore the mitigating role of support resources on child outcomes are presented in Table 2 . With regard to the MDI, the regression model was significant, $\mathrm{F}(7,51)=6.310, p<.001$. Maternal prenatal eating disorder accounted for $14 \%$ of the variance. The addition of maternal functioning factors accounted for more than twice the variance (30\%), however only organization of the home environment emerged as a significant predictor. Support resources indices added 7\%, but only extended social support significantly predicted the toddler's mental development. We also found a significant interaction of maternal stress X extended social support, accounting for an additional $6 \%$ of the variance of the MDI. Examination of this interaction revealed that among mothers with low maternal stress, higher social support was correlated with higher mental development $(\mathrm{r}=.59, p<.001)$, whereas among mothers with high maternal stress, extended social support was not correlated with mental development outcome ( $\mathrm{r}=.17$, ns). We decomposed this significant interaction through follow-up simple slopes analyses testing the associations between maternal stress

\begin{tabular}{|c|c|c|c|c|c|c|c|}
\hline \multicolumn{4}{|l|}{ Mental Developmental Index ${ }^{a}$} & \multicolumn{4}{|l|}{ Psychomotor Developmental Index ${ }^{b}$} \\
\hline Variable & B & SE B & $\beta$ & Variable & B & SE B & $\beta$ \\
\hline \multicolumn{4}{|l|}{ Step 1: Maternal prenatal eating disorder } & \multicolumn{4}{|l|}{ Step 1: Maternal prenatal eating disorder } \\
\hline Eating disorder vs. Control & -8.40 & 2.83 & $-.37^{\star *}$ & Eating disorder vs. Control & -9.59 & 2.70 & $-.43^{* *}$ \\
\hline \multicolumn{4}{|l|}{ Step 2: Maternal functioning } & \multicolumn{4}{|l|}{ Step 2: Maternal functioning } \\
\hline Maternal stress & 2.50 & 2.67 & .01 & Maternal stress & -.60 & 2.76 & -.03 \\
\hline Organization of the home environment & .30 & .09 & $.46^{\star *}$ & Organization of the home environment & .14 & .09 & .22 \\
\hline \multicolumn{4}{|l|}{ Step 3: Support resources } & \multicolumn{4}{|l|}{ Step 3: Support resources } \\
\hline Partner support & -.94 & 1.36 & -.09 & Partner support & -2.69 & 1.43 & -.29 \\
\hline Extended social support & 3.75 & 1.57 & $.30^{*}$ & Extended social support & 2.14 & 1.64 & .17 \\
\hline Step 4: Interaction & & & & Step 4: Interaction & & & \\
\hline Maternal stress $X$ extended social support & -4.92 & 2.24 & $-.25^{\star}$ & Maternal stress $X$ extended social support & -6.37 & 2.29 & $-.33^{* *}$ \\
\hline
\end{tabular}

${ }^{a} \mathrm{MDI}: \mathrm{R}^{2}=.14$ for Step 1, .30 for Step 2, .37 for Step 3, .43 for Step 4; $\Delta \mathrm{R}^{2}=.16$ for Step 2, .07 for Step 3, .06 for Step 4 ( $p<.05$ )

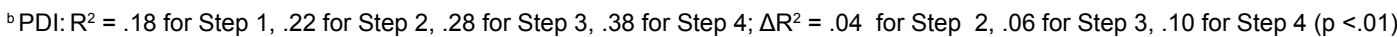

${ }^{*} p<.05 ;{ }^{* *} p<.01$

Table 2: Hierarchical Regression Analyses Predicting Toddler Mental and Psychomotor Development from Maternal Prenatal Eating Disorder, Maternal Functioning and Support Resources. 
and extended social support with high versus low levels of support (+1 SD above and (-1 SD below the mean, respectively). For mothers with high maternal stress, there was no association between high social support and child mental development $\left(B=-0.81, \mathrm{SE}_{\mathrm{B}}=3.44, t=0.23\right.$, $p=.81$ ), while lower social support was significantly associated with higher $\mathrm{MDI},\left(B=8.36, \mathrm{SE}_{\mathrm{B}}=3.22, t=2.59, p=.01\right)$.

In regard to the PDI, the regression model was significant as well, $\mathrm{F}(7,51)=5.18, p<.001$. Maternal prenatal eating disorder explained $18 \%$ of the variance. In Step 2 and 3, maternal functioning and support resources added $4 \%$ and $6 \%$, respectively, however none of the factors was a significant predictor alone. The interaction of maternal stress $\mathrm{X}$ extended social support accounted for additional $10 \%$ of the variance of the PDI. Follow-up simple slopes analyses found that among mothers with high maternal stress, lower social support was not correlated with psychomotor development outcomes $\left(B=5.42, \mathrm{SE}_{\mathrm{B}}=3.29, t=1.65\right.$, $p=.11$ ). However, for mothers with high maternal stress and greater social support, there was a nonsignificant decrease in children's psychomotor scores $\left(B=-6.45, \mathrm{SE}_{\mathrm{B}}=3.52, t=1.83, p=.07\right)$ (Table 2$)$.

\section{Discussion}

High anxiety, low self-efficacy and a sense of social isolation are often a part of the adult course of eating disorders [38]. Understandably, these characteristics may be associated with adverse maternal and child functioning among the offspring of mothers with eating disorders. This study operationalized three factors of the complex matrix of toddlers' development, following earlier reports of a developmental delay in the toddlers of mothers with eating disorders [11]. Findings suggest that mothers' prenatal eating disorder history, higher parenting-related stress and lower cognitive stimulation of the child, as well as weaker support networks, are linked to compromised neurodevelopmental outcomes in the toddlers. Further, higher extended social support was associated in this study with better child outcomes only for mothers who had lower maternal stress.

Interestingly, the support provided by spouses did not mitigate the links between the maternal eating disorder and the child's development. The mother's perception of the help she has (i.e., whether she feels comfortable receiving support or sharing her difficulties with her partner) mediates her ability and willingness to make good use of this support [39]. Additionally, the spouses of mothers with eating disorders have previously been found to have higher psychopathological symptoms than the partners of control mothers, and their anxiety and obsessive/compulsive symptoms were associated with disrupted psychological functioning in their children [40]. Thus, uncovering adapted ways to increase spousal support and communication is fundamental in any prevention and promotion efforts delivered to the children of mothers with eating disorders [41].

Strengths of this study include the use of case-control pairs matched for central covariates in neurocognitive development, and the fact that the maternal eating disorder diagnosis and child development were assessed by experts and not according to self-report. Limitations include the single assessment of cognitive development, the isolation of maternal functioning and child development without assessing other factors that contribute to child outcomes, including socioeconomic status and the second parent's functioning. Additionally, the mothers in this study were possibly a relatively less remittent group, thus limiting the external validity of the study. Finally, the current study is cross-sectional and cannot assess causality between maternal eating disorders and child development. However, maternal reports on the temporal association between the onset of their eating disorder and when they became mothers (14 years on average) imply that the maternal mental state may partly affected parental practices and the mother-child relationship $[42,43]$.

The current exploratory study extends the literature on the links between maternal eating disorders and broader adversities in their young children, beyond the associations with feeding and eating problems, thereby suggesting a greater risk of no adaptive developmental trajectories. Additionally, this study operationalized dimensions of compromised maternal functioning and spousal support that are linked to adverse outcomes in toddlers that should be studied in adequately powered samples, and could be targeted in focused parent-based preventive intervention programs for families in which the mother has an eating disorder history.

\section{Funding}

Dr. Sadeh-Sharvit conducted this study with the financial support of the President's Doctoral Fellowship of Excellence, Bar Ilan University.

\section{Conflicts of interest}

The authors declare no conflict of interest

\section{References}

1. Siegenthaler E, Munder T, Egger M (2012) Effect of Preventive Interventions in Mentally III Parents on the Mental Health of the Offspring: Systematic Review and Meta-Analysis. Journal of the American Academy of Child and Adolescent Psychiatry 1: 8-17.

2. Wachs TD, Black MM, Engle PL (2009) Maternal depression: A global threat to children's health, development, and behavior and to human rights. Child Development Perspectives 3: 51-59.

3. Hammen C, Brennan PA (2003) Severity, chronicity and timing of maternal depression and risk for adolescent offspring diagnoses in a community sample. Arch Gen Psychiatry 60: 253-258.

4. Agras S, Hammer L, Mc Nicholas F (1999) A prospective study of the influence of eating-disordered mothers on their children. Int J Eat Disord 25: 253-262.

5. Allen KL, Gibson LY, McLean NJ, Davis EA, Byrne SM (2014) Maternal and family factors and child eating pathology: risk and protective relationships. J Eat Disord 2: 11

6. Hoffman ER, Bentley ME, Hamer RM, Hodges EA, Ward DS, et al. (2014) A comparison of infant and toddler feeding practices of mothers with and without histories of eating disorders. Matern Child Nutr 10: 360-372.

7. Micali N, Simonoff E, Treasure J (2007) Risk of major adverse perinata outcomes in women with eating disorders. Br J Psychiatry 190: 255-259.

8. Stein A, Woolley H, Cooper SD, Fairburn CG (1994) An observational study of mothers with eating disorders and their infants. J Child Psychol Psychiatry 35: 733-748

9. Johnson PL, Falke EM (2007) Maternal depression and child outcomes. Pediatr Ann 36: 196-202.

10. Sadeh-Sharvit S, Levy-Shiff R, Lock JD (2015) Maternal Eating Disorder History and Toddlers' Neurodevelopmental Outcomes: A Brief Report. Eat Disord 25: 1-9.

11. Kothari R, Rosinska M, Treasure J, Micali N (2014) The early cognitive development of children at high risk of developing an eating disorder. Eur Eat Disord Rev 22: 152-156.

12. Kothari R, Solmi F, Treasure J, Micali N (2013) The neuropsychological profile of children at high risk of developing an eating disorder. Psychol Med 43: 1543-1554.

13. Zerwas S, Von Holle A, Torgersen L, Reichborn-Kjennerud T, Stoltenberg C, et al. (2012) Maternal eating disorders and infant temperament: findings from the Norwegian mother and child cohort study. Int J Eat Disord 45: 546-555.

14. Easter A, Howe LD, Tilling K, Schmidt U, Treasure J, et al. (2014) Growth trajectories in the children of mothers with eating disorders: a longitudinal study. BMJ Open 4: e004453. 
Citation: Sadeh-Sharvit S, Levy-ShiffR, Arnow KD, Lock JD (2015) The Impact of Maternal Eating Disorders and Spousal support on Neurodevelopmental Trajectories in their Toddlers. Abnorm Behav Psychol 1: 102. doi:10.4172/2472-0496.1000102

15. Sadeh-Sharvit S, Levy-Shiff R, Feldman T, Ram A, Gur E, et al. (2015) Child feeding perceptions among mothers with eating disorders. Appetite 95: 67-73.

16. Martin A, Ryan RM, Brooks-Gunn J (2010) When fathers' supportiveness matters most: Maternal and paternal parenting and children's school readiness. Journal of Family Psychology 24: 145-155.

17. Linver MR, Brooks-Gunn J, Kohen DE (2002) Family processes as pathways from income to young children's development. Dev Psychol 38: 719-734.

18. Squires C, Lalanne C, Murday N, Simoglou V, Vaivre-Douret L (2014) The influence of eating disorders on mothers' sensitivity and adaptation during feeding: A longitudinal observational study. BMC Pregnancy and Childbirth 14: 274

19. Crnic KA, Gaze C, Hoffman C (2005) Cumulative parenting stress across the preschool period: Relations to maternal parenting and child behaviour at age 5 . Infant and Child Development 14: 117-132.

20. Hoffman ER, Hodges EA, Propper C, Postage PL, Zipkin EC, et al. (2013) Behavioral and Psychophysiological Responsiveness During Child Feeding in Mothers with Histories of Eating Disorders: A Pilot Study. J Psychopathol Behav Assess 35: 578-591.

21. Dunn ME, Burbine T, Bowers CA, Tantleff-Dunn S (2001) Moderators of stress in parents of children with autism. Community Ment Health J 37: 39-52.

22. Levy-Shiff R, Lerman M, Har-Even D, Hod M (2002) Maternal adjustment and infant outcome in medically defined high-risk pregnancy. Dev Psychol 38: 93-103.

23. Carr A (2009) The effectiveness of family therapy and systemic interventions for child-focused problems. Journal of Family Therapy 31: 3-45.

24. Diamond G, Josephson A (2005) Family-based treatment research: a 10-year update. J Am Acad Child Adolesc Psychiatry 44: 872-887.

25. Riley AW, Valdez CR, Barrueco S, Mills C, Beardslee W, et al. (2008) Development of a family-based program to reduce risk and promote resilience among families affected by maternal depression: theoretical basis and program description. Clinical Child and Family Psychology Review 11: 12-29.

26. Lock J (2011) Evaluation of family treatment models for eating disorders. Curr Opin Psychiatry 24: 274-279.

27. Association AP (2000) Diagnostic and statistical manual. (4 $4^{\text {th }}$ edition), Tex Revision (DSM-IV-TR), American Psychiatric Association, Washington.

28. Garner DM (1991) Eating disorder inventory-2. Psychological assessment resources Odessa, FL.

29. Abidin R (1995) Parenting Stress Index: Professional Manual. (3 $3^{\text {rd }}$ edition), FL: Psychological Assessment Resources, Odessa.
30. Sullivan K, Clark J, Castrucci B, Samsel R, Fonseca V, et al. (2011) Continuing education mitigates the negative consequences of adolescent childbearing Matern Child Health J 15: 360-366.

31. Crnic KA, Greenberg MT, Slough NM (1986) Early stress and social support influences on mothers' and high-risk infants' functioning in late infancy. Infant Mental Health Journal 7: 19-33.

32. Bayley N (1993) Bayley scales of infant development: Manual. Psychological Corporation.

33. Levy-Shiff R, Dimitrovsky L, Shulman S, Har-Even D (1998) Cognitive appraisals, coping strategies, and support resources as correlates of parenting and infant development. Dev Psychol 34: 1417-1427.

34. Garner DM, Olmsted MP, Bohr Y, Garfinkel PE (1982) The eating attitudes test: psychometric features and clinical correlates. Psychological medicine 12 871-878.

35. Easter A, Treasure J, Micali N (2011) Fertility and prenatal attitudes towards pregnancy in women with eating disorders: results from the Avon Longitudinal Study of Parents and Children. BJOG: An International Journal of Obstetrics and Gynaecology 118: 1491-1498.

36. Baron RM, Kenny DA (1986) The moderator-mediator variable distinction in social psychological research: Conceptual, strategic, and statistical considerations. Journal of personality and social psychology 51: 1173-1183.

37. IBM-Corp (2013) IBM SPSS Statistics for Windows Version 22.0. IBM Corp: Armonk, NY.

38. Blissett J, Meyer C, Farrow C, Bryant-Waugh R, Nicholls D (2005) Maternal core beliefs and children's feeding problems. Int J Eat Disord 37: 127-134.

39. Balaji AB, Claussen AH, Smith DC, Visser SN, Morales MJ, et al. (2007) Social support networks and maternal mental health and well-being. J Womens Health (Larchmt) 16: 1386-1396.

40. Cimino S, Cerniglia L, Paciello M, Sinesi S (2013) A six-year prospective study on children of mothers with eating disorders: the role of paternal psychological profiles. Eur Eat Disord Rev 21: 238-246.

41. Beardslee WR, Gladstone TR (2014) Mental Illness Prevention and Promotion, in the Challenges of Mental Health Caregiving. Springer: 83-102.

42. Johnson JG, Cohen P, Chen H, Kasen S, Brook JS (2006) Parenting behaviors associated with risk for offspring personality disorder during adulthood. Arch Gen Psychiatry 63: 579-587.

43. Weissman MM, Pilowsky DJ, Wickramaratne PJ, Talati A, Wisniewski SR, et al. (2006) Remissions in maternal depression and child psychopathology: a STAR*D-child report. JAMA 295: 1389-1398. 